\title{
Grey zone lymphomas
}

\section{J. H. van Krieken}

Published online: 1 July 2014

(C) Springer-Verlag Berlin Heidelberg 2014

Recently, John Goodlad and his team organised an interesting workshop on borderline or grey zone lymphomas in Edinburgh. The workshop was case based and it was interesting to see what the teachers had selected: lymphoproliferations that did not fit well in an entity of the 2008 WHO classification or belong to a provisional not yet well-defined category in the Blue Book. Such cases are of course food for thought: why do we have borderline or grey zone lymphomas? Do we have insufficient criteria or is biology too complex for our classification schemes?

We base our entities on morphological, immunophenotypical, genetic and clinical features and for some cases morphology is the most important (Hodgkin's lymphoma, T cell-rich B cell lymphoma), for others clinical features are critical (mediastinal diffuse large B cell lymphoma). Having such a variety of criteria tells us that we still have insufficient understanding of lymphomagenesis. Real understanding would lead to a cause/ pathogenesis-based classification and we are not very close to that. Even if we know a main cause of a lymphoma, we still can put the lymphoma in different entities: EBV-positive lymphomas are present in many chapters of the WHO-book.

Some of our criteria can be shaky. Phenotype is an important criterion, but one to be used with caution. Cancer cells do not behave normal so it should not come as a surprise that cancer cells may have aberrant protein expression. That is why we use so many markers. Some B cell lymphomas have expression of $\mathrm{T}$ cell markers and vice versa so other unusual expression may be expected as well. Furthermore, cells change their expression when they come in a different environment.

Some lymphomas are characterised by a specific genetic alteration, but there are always exceptions. Gene expression arrays are used in a research setting and is able to make more or less homogenous groups, but is also clear that classifier needs many genes and that this approach cannot be used for single cases. It is also not yet possible to translate for instance the two main groups of diffuse large B cell lymphoma into easy immunophenotypical-defined entities. So we are far from a molecular classification.

The conclusion could be that we need a paradigm shift for classification, but that we lack the knowledge or ideas to bring that about. Grey zone lymphomas challenge us and we have sometimes problems with them, but they may be the driver for new ideas. In the meantime, we need to serve our patients and it was interesting to see that for all cases that were not easy to classify, an advise for treatment could be formulated. Therefore, the final conclusion of the workshop was that with enough knowledge and data we are able to deal with great majority of lymphoproliferations in a reliable way.
J. H. van Krieken $(\bowtie)$

Department of Pathology, Radboud University Nijmegen Medical Centre, P.O. box 9101, 6500 HB Nijmegen, The Netherlands

e-mail: J.vankrieken@pathol.umcn.nl 